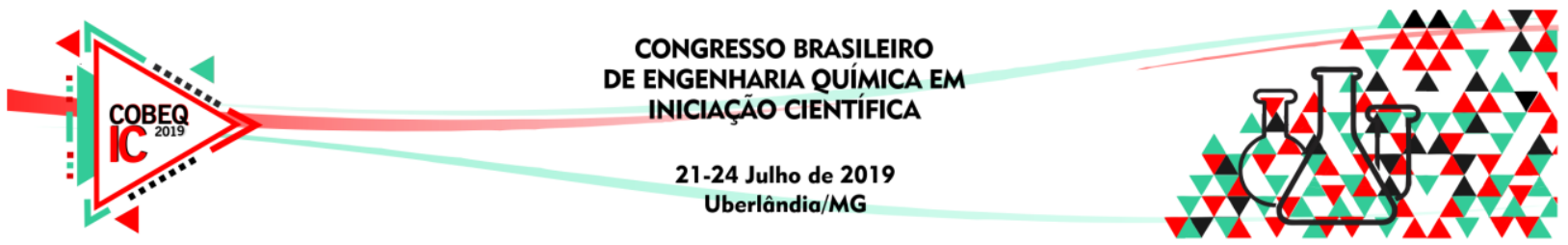

\title{
EXTRAÇÃO DE CORANTE - MÉTODO ARTESANAL
}

\author{
B.R. FREITAS ${ }^{1}$, B.A. ROCHA ${ }^{1}$, P.S.S. SANTOS ${ }^{1}$, A.B. REIS ${ }^{1}$ \\ ${ }^{1}$ Universidade Federal dos Vales do Jequitinhonha e Mucuri, Departamento de \\ Engenharia Química \\ E-mail para contato: barbara.rodrigues95@ hotmail.com
}

\begin{abstract}
RESUMO - A obtenção de corantes para o tingimento de variados tecidos e/ou superfícies é uma técnica utilizada desde a antiguidade por muitas nações espalhadas pelo mundo. Com o avanço da indústria e as novas tendências mundiais, se busca, cada vez mais, incorporar ao processo, práticas que contribuam para a manutenção do bem-estar do meio ambiente e que objetivam uma rentabilidade desejada. No presente trabalho, foram realizados estudos da extração de corante, de forma artesanal, do bagaço da cana-de-açúcar e da serragem de madeira, ambos rejeitos de indústrias, com intuito de aumentar suas aplicabilidades, comparando suas ações com a de corantes já conhecidos comercialmente. Os materiais foram tratados e conduzidos aos testes com auxílio de operações unitárias como moagem, peneiramento, extração, secagem, centrifugação. A partir dos resultados foi possível observar uma maior eficiência e tingimento do corante proveniente do bagaço da cana-de-açúcar.
\end{abstract}

\section{INTRODUÇÃO}

O estudo da possibilidade de se extrair, artesanalmente, corantes de rejeitos industriais com auxílio de operações unitárias como: moagem do material, classificação granulométrica, cálculo de densidade entre outros, partiu da tentativa de conciliar os altos impactos ambientais causados pela indústria tanto na exacerbada produção de corantes artificiais, que afetam a natureza poluindo efluentes e solos, quanto à quantidade de materiais descartados nos processos por possuírem baixa aplicação. Os rejeitos escolhidos para estudo foram o bagaço da cana-de-açúcar e a serragem de madeira.

A extração de corantes é um regime que exige que o material seja induzido a alguns processos preliminares para que esta aconteça. A escolha do solvente é de suma importância, e depende da afinidade do mesmo com o material que servirá de matériaprima. Em técnicas artesanais, o uso mais frequente é o de água, conhecida por sua ação como solvente natural. A escolha do solvente se dá também pela afinidade deste com o soluto desejado e deve ser preferivelmente de baixa viscosidade para melhor escoamento. Outros compostos como álcoois e cetonas também podem realizar esta função, alinhados à produção sintética de corantes (FILHO, 2017).

Fibras de origem animal ou vegetal podem ser usadas para tingimento ao se ter a formação de um tecido a partir desses materiais, através da mudança de coloração 


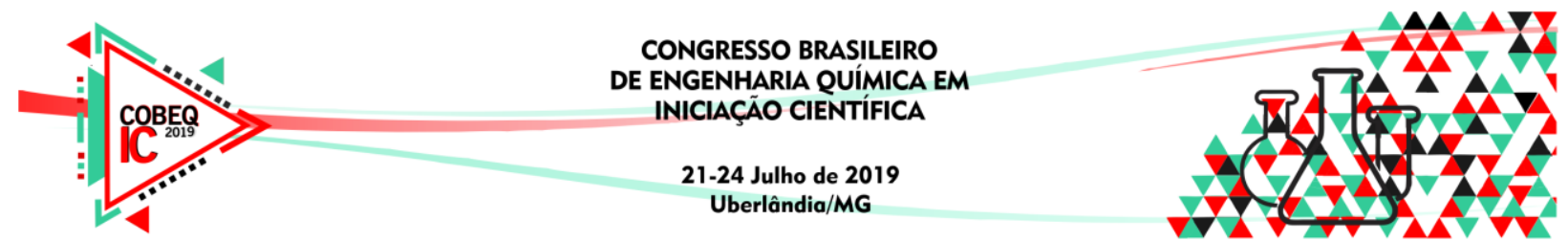

quando em contato com o corante. A eficiência do corante pode mudar de acordo com a fibra a ser tingida. O papel é um material de fibra de fonte vegetal, que pode ser tingido por corantes (ARAÚJO, 2006). No âmbito desse contexto, afim de analisar a qualidade do revestimento, mesmo que visualmente, o presente trabalho aplicou as soluções de corantes obtidas artesanalmente em amostras de papel vergê (gramatura 180g).

\section{METODOLOGIA}

Para realização do presente estudo, inicialmente, foram pesados, em uma balança, $206 \mathrm{~g}$ da amostra de bagaço de cana de açúcar e 200g da amostra de serragem de madeira. Em seguida as amostras foram submetidas à moagem, em moinho de facas Lucadema com lâmina de mesh 10, durante o intervalo de 6 minutos. Em estudos anteriores comprovou-se que a lâmina com o mesh 10 proporciona maior área de contato entre os grãos e as soluções corantes a serem preparadas posteriormente.

Em seguida as amostras foram submetidas à análise de distribuição granulométrica utilizando-se um jogo de peneiras Tyler e mesa vibratória Bertel, viabilizando assim a escolha das amostras retidas nas peneiras de 25, 35, 50 e 70 mesh. Para cada amostra foram preparadas quatro soluções de corante, a partir de partículas com diâmetro de aproximadamente $710,500,300$ e $212 \mathrm{~mm}$ e da primeira seleção das frações retidas nas peneiras $25,35,50$ e 70 mesh. No intuito de padronizar as quatro soluções corante, preparadas para cada amostra de bagaço de cana de açúcar e de serragem de madeira, foram então preparadas soluções-corante, alternando os solventes: água e acetona.

Para o preparo de cada solução de corante utilizando como solvente a água, foram separados $10 \mathrm{~g}$ de cada fração retida das peneiras para $100 \mathrm{~mL}$ de água. Tais soluções, separadamente, foram submetidas à fervura até atingirem aproximadamente $110^{\circ} \mathrm{C}$, e em seguida, sujeitas a técnica de filtração à vácuo, resultando assim no soluto intitulado "solução corante-água", armazenado em tubos falcon a fim de ser analisada posteriormente. Para a solução corante utilizando como solvente acetona, foram separados 2,5g de cada fração retida nas peneiras para $25 \mathrm{~mL}$ de acetona e, em seguida, cada uma das soluções foram deixadas em repouso durante 20 minutos. Após esse tempo as soluções foram submetidas à filtração à vácuo, resultando assim no soluto intitulada "solução corante-acetona", armazenada em tubos falcon a fim de ser analisada posteriormente.

Após o preparo de todas as soluções, tanto para as amostras de bagaço de cana de açúcar quanto para as amostras de serragem de madeira, estas permaneceram em repouso por aproximadamente 17 horas. Em seguida, todas as soluções foram submetidas a ação da centrífuga, durante 5 minutos com uma rotação de 2400 rpm.

E então, para cada uma das soluções foi realizada a análise de espectrometria UVVIS. E por fim, mantiveram-se imersos distintos filetes de papel verge branco em cada uma das soluções corante por um período de duas horas, que logo após, tais filetes foram deixados na estufa de circulação de ar a $104{ }^{\circ} \mathrm{C}$ por aproximadamente 17 horas. 


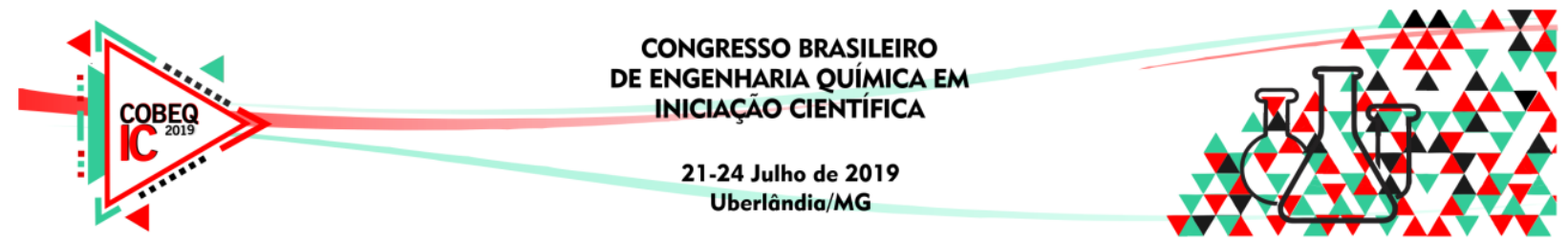

Para fins analíticos o preparo da solução do corante de urucum se fez necessário. Atribui-se a mistura entre a amostra do corante A-720-ES-AP com água destilada. Para a solução padrão foram utilizados 0,51g de amostra e 9,57g de água. A partir da amostra padrão foram preparadas 4 soluções distintas, contendo $10 \mathrm{~g}$ de cada uma das frações anteriormente retidas. Logo, foram preparadas 4 soluções nas proporções de $10 \mathrm{~g}$ de partículas diluídas em $100 \mathrm{~mL}$ de água e 4 soluções corante nas proporções de $10 \mathrm{~g}$ de partículas para diluídas em $100 \mathrm{~mL}$ de acetona, descritas na Tabela 1.

Tabela 1 - Solução de corante de urucum

\begin{tabular}{|c|c|}
\hline Solução & $\begin{array}{c}\text { Porcentagem da } \\
\text { solução padrão } \\
(\%)\end{array}$ \\
\hline \hline 0 & 0 \\
\hline 1 & 10 \\
\hline 2 & 8 \\
\hline 3 & 6 \\
\hline 4 & 4 \\
\hline
\end{tabular}

\section{RESULTADOS E DISCUSSÕES}

Com as concentrações conhecidas das soluções de corante de urucum, foi possível gerar uma curva padrão, observada na Figura 1.

Figura 1 - Gráfico Curva Padrão

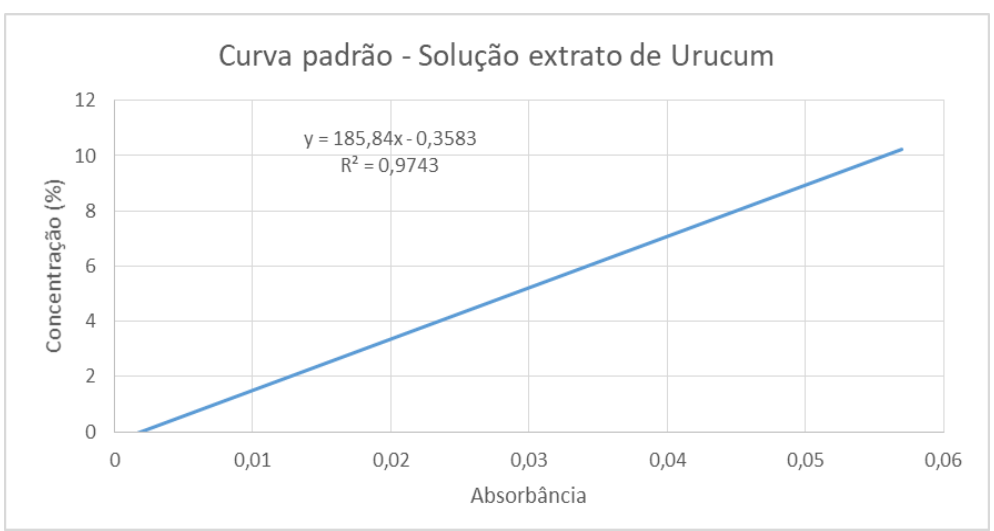

Foi realizada para cada amostra uma análise espectrofotométrica UV visível dos compostos corantes extraídos, e partir de uma curva padrão foi possível determinar a concentração de extrato presenta em cada amostra, tais resultados obtidos são demonstrados nas Tabelas 2 e 3.

Dentre os resultados para extrato de Bagaço de Cana, a maior absorbância foi para a extração realizada com água como solvente e com 100 MESH. Podemos observar nas Figuras 2 e 3 que curva apresentou um comportamento linear como era o esperado. 


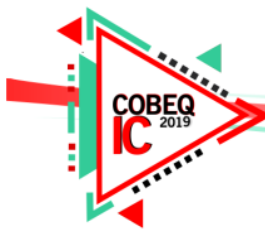

21-24 Julho de 2019

Uberlândia/MG

Tabela 2 - Dados Extrato de Bagaço

\begin{tabular}{|c|c|c|c|c|c|}
\hline \multicolumn{5}{|c|}{ Extrato do Bagaço } \\
\hline \hline \multicolumn{3}{|c|}{ Acetona } & \multicolumn{3}{c|}{ Água } \\
\hline \hline Absorbância & Mesh & $\begin{array}{c}\text { Concentração } \\
(\%)\end{array}$ & Absorbância & Mesh & $\begin{array}{c}\text { Concentração } \\
(\%)\end{array}$ \\
\hline \hline 0,033 & 100,000 & 5,774 & 0,168 & 100,000 & 30,863 \\
\hline 0,065 & 48,000 & 11,721 & 0,136 & 48,000 & 24,916 \\
\hline 0,033 & 32,000 & 5,774 & 0,071 & 32,000 & 12,836 \\
\hline 0,024 & 24,000 & 4,102 & 0,065 & 24,000 & 11,721 \\
\hline
\end{tabular}

Figura 2 - Curva extrato de Bagaço com Acetona como solvente

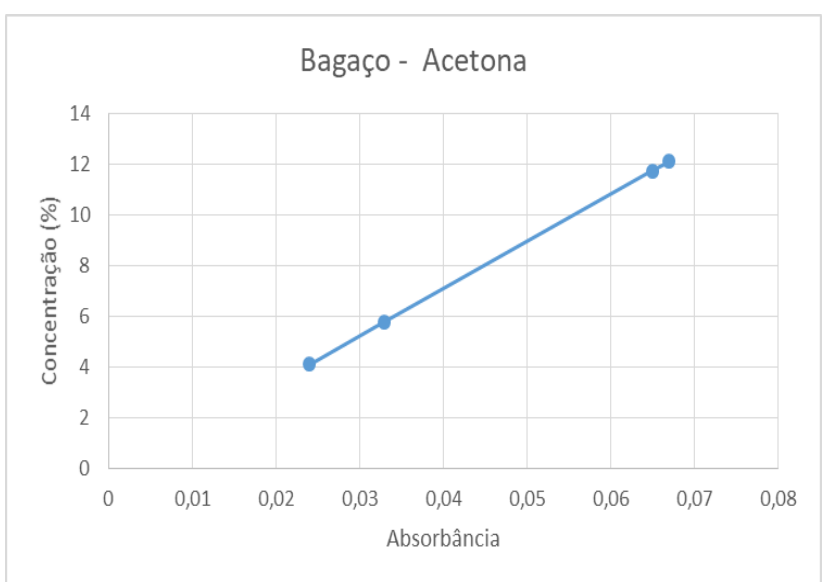

Figura 3 - Curva extrato de Bagaço com Água como solvente

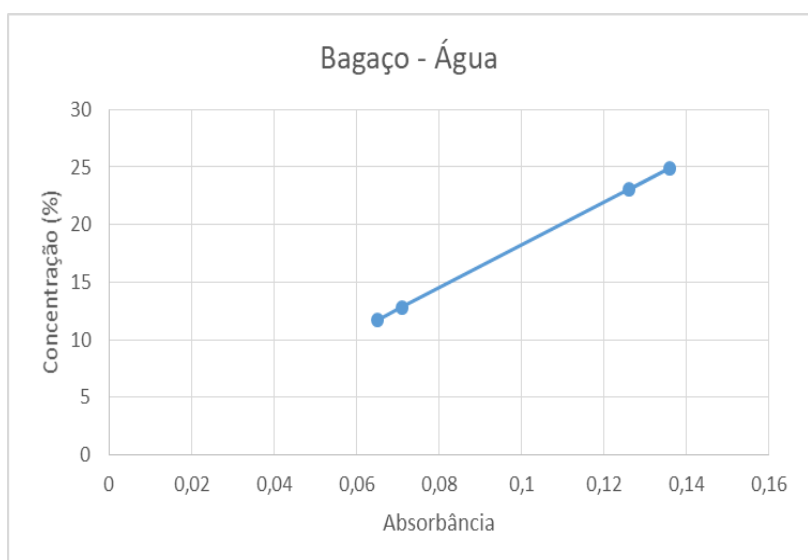

Tabela 3 - Dados Extrato de Serragem

\begin{tabular}{|c|c|c|c|c|c|}
\hline \multicolumn{7}{|c|}{ Acetona } & \multicolumn{3}{c|}{ Água } \\
\hline \hline Absorbância & Mesh & $\begin{array}{c}\text { Concentração } \\
(\%)\end{array}$ & Absorbância & Mesh & $\begin{array}{c}\text { Concentração } \\
(\%)\end{array}$ \\
\hline \hline 0,216 & 65,000 & 39,783 & 0,765 & 65,000 & 141,809 \\
\hline 0,448 & 48,000 & 82,898 & 0,822 & 48,000 & 152,402 \\
\hline 0,153 & 32,000 & 28,075 & 0,843 & 32,000 & 156,305 \\
\hline 0,609 & 24,000 & 112,818 & 1,170 & 24,000 & 217,075 \\
\hline
\end{tabular}

Dentre os resultados para extrato da serragem, a maior absorbância foi para a extração realizada com água como solvente e com $24 \mathrm{MESH}$. Mas para uma verificação mais rigorosa, como a concentração dos extratos é dada em porcentagem, as amostras com água deveriam ser diluídas, pois temos concentrações maiores que $100 \%$ para todos os tamanhos de partículas. Podemos observar nas Figuras 4 e 5 que as curvas apresentaram um comportamento linear como era o esperado. 


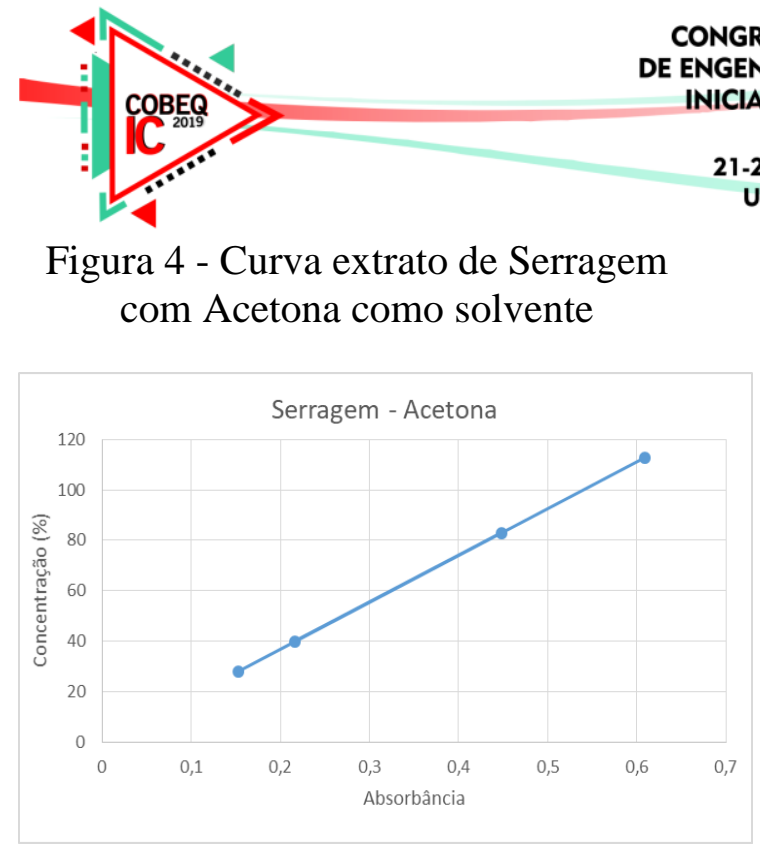

Figura 5 - Curva extrato de Serragem com Água como solvente

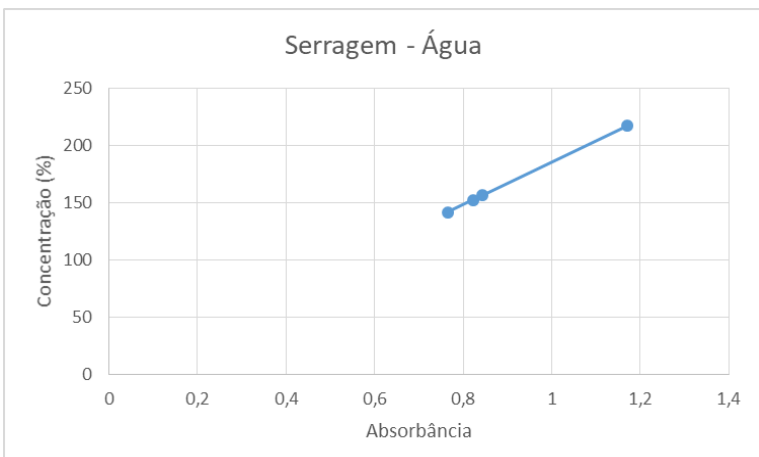

Os melhores valores de absorbância estão demonstrados na Figura 6.

Figura 6 - Gráfico comparação melhores valores de absorbância

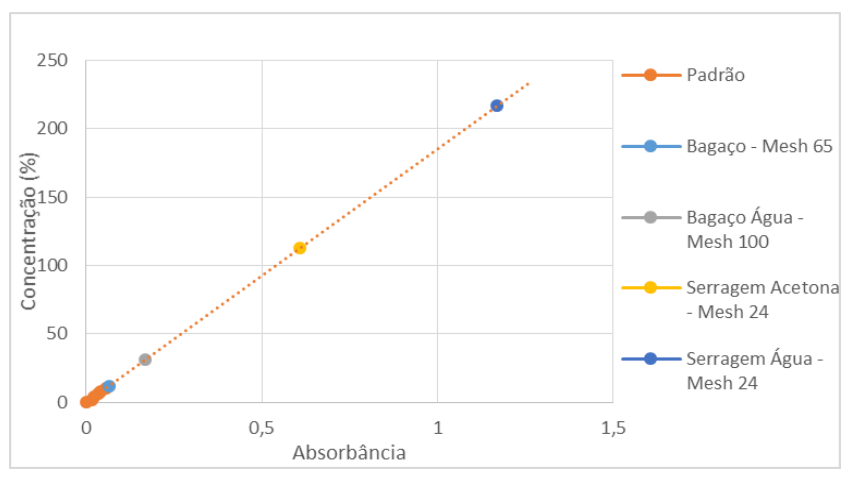

Afim de verificar a eficiência da extração de corantes, foi realizado teste de tingimento de papel vergê branco. Conforme ilustram as Figuras 7 e 8, foi possível tingir as amostras de papel vergê com os extratos. Foi possível também inferir que, a eficiência da tonalidade do tingimento está relacionada com as diferentes propriedades como: tamanho da partícula e escolha do solvente.

Figura 7 - Papeis tingidos pelos extratos de Bagaço

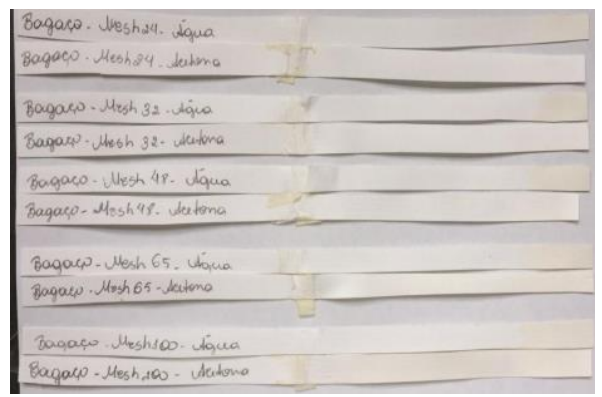

Figura 8 - Papeis tingidos pelos extratos de serragem

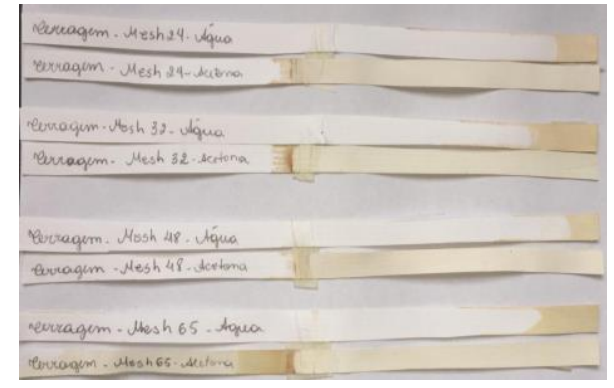

Esses resultados mostram que a extração artesanal de bagaço e serragem são eficientes. 
Estudo da influência do Tamanho da Partícula: Segundo Alves (2018) quanto menor o tamanho da partícula, maior a superfície de contato, então mais eficiente será a extração de corante. Para o extrato de bagaço, conforme o esperado, ocorreu uma melhora na transferência do soluto com a redução do diâmetro da partícula, devido à maior área superficial. Com isso o tamanho da partícula com maior absorbância foi o de 100 MESH. Já para o extrato de serragem não aconteceu o esperado, os melhores resultados foram para as partículas maiores, $24 \mathrm{MESH}$.

Nesse estudo foram utilizados os solventes: água e a acetona. As extrações realizadas com água obtiveram melhores resultados, e acredita-se que seja por uma maior afinidade com os materiais, gerando maior solubilização, aumentando a concentração de extrato.

\section{CONCLUSÃO}

Com fundamento nas bibliografias e conhecimentos prévios. Durante a realização dos procedimentos, foi possível se extrair o corante dos materiais, bagaço de cana e serragem. Após se aplicarem todos os processos descritos neste trabalho, foi feita análise visual acerca da qualidade do tingimento das amostras de papel vergê. Tal observação visual possibilitou concluir que o tingimento propiciado por corante extraído com o solvente água teve maior eficácia do que o proveniente de acetona. Ao se relacionar o tamanho da partícula com a absorbância obtida em cada corante extraído, era de se esperar que os corantes provenientes de partículas menores tivessem uma maior dimensão, o que, de fato, foi observado no corante de origem do bagaço da cana. O corante de origem da serragem, no entanto, teve sua absorbância fora do esperado, o que pode ter sido fruto de erros nas leituras no espectrofotômetro ou distinção da liberação do corante em relação ao bagaço de cana-deaçúcar.

Depreende-se, pelos resultados, o cumprimento do objetivo de se obter corantes, de forma artesanal, através de rejeitos de indústrias, possibilitando a estes um novo aproveitamento, além de ser um processo propiciado por vários fatores já que sua maior eficácia partiu de um solvente mais barato e as operações realizadas durante o processo também possuem baixo custo à indústria que se pôr a realizá-lo.

\section{REFERÊNCIAS}

ALVES, R. C. Influência da granulometria do bagaço de cana-de-açúcar na solubilização de hemicelulose e produção de açúcares fermentáveis. Programa de pós-graduação em Microbiologia Aplicada - Dissertação apresentada ao Instituto de Biociências do Campus de Rio Claro, Universidade Estadual Paulista, 2018.

ARAÚJO, M. E. M. de. Corantes naturais para têxteis - da Antiguidade aos tempos modernos. Conservar Património 2006. Disponível em: <http://uaech.redalyc.org/articulo.oa?id=513653427004> ISSN. Acesso em: 13 de março de 2018.

FILHO, J. F. de O. Extração de corante natural a partir do resíduo da uva. 2017. Trabalho de Conclusão de Curso de Engenharia Química - Departamento de Engenharia Química, Universidade Federal do Rio Grande do Norte, Natal. 